Saudi Journal of Biomedical Research

Abbreviated Key Title: Saudi J Biomed Res ISSN 2518-3214 (Print) |ISSN 2518-3222 (Online) Scholars Middle East Publishers, Dubai, United Arab Emirates Journal homepage: https://saudijournals.com

\title{
In Vitro Anti Thiamine Activity of Bergenia ciliata leaves of Sikkim Himalaya: Effect of Solvent, Temperature, pH and Duration of Extraction Process
}

Tanaya Ghosh ${ }^{1}$, Prasanta Kumar Mitra ${ }^{1 *}$

${ }^{1}$ Department of Medical Biotechnology, Sikkim Manipal University, Sikkim Manipal Institute of Medical Sciences, Gangtok, Sikkim, India

DOI: $10.36348 /$ sjbr.2022.v07i01.004

| Received: 09.12.2021 | Accepted: 22.01.2022 | Published: 29.01.2022

*Corresponding author: Prasanta Kumar Mitra

Department of Medical Biotechnology, Sikkim Manipal University, Sikkim Manipal Institute of Medical Sciences, Gangtok, Sikkim, India

\section{Abstract}

Effect of solvent, temperature, $\mathrm{pH}$ and time on extraction process of anti-thiamine factor present in Bergenia ciliate leaves was studied. Results showed that extraction of the leaf-extract with ethanol at $40^{\circ} \mathrm{C}$ for 15 minutes at $\mathrm{pH} 3.0 \mathrm{had}$ maximum anti-thiamine activity in in vitro experiments

Keywords: Extraction process, Anti-thiamine factor, Bergenia ciliate.

Copyright ( $\mathbf{2 0 2 2}$ The Author(s): This is an open-access article distributed under the terms of the Creative Commons Attribution 4.0 International License (CC BY-NC 4.0) which permits unrestricted use, distribution, and reproduction in any medium for non-commercial use provided the original author and source are credited.

\section{INTRODUCTION}

Bergenia ciliata (B. ciliata), familySaxifragacae, popularly known as 'Paashanbheda' (meaning 'to dissolve the stone'), is one of the important medicinal plants of Sikkim Himalaya. The plant has spirally arranged of rosette of leaves. Leaves are glabrous or hirsute, suborbicular to orbicular broadly obovate, base cordate or sometimes rounded and apex round in shape. Flowers, produced in cyme, are pink to purplish. Sepals are pink to red. Carpels and styles are green or pinkish. Seeds are elongated about 1 $\mathrm{mm}$ long, minutely tuberculate, usually numerous, albuminous. Stamens are inserted with the petals, equaling or double their number. Rhizomes are compact solid, somewhat cylindrical barrel shaped, longitudinally wrinkled, covered with root scars, possess a characteristic, slightly camphoraceous odour and pungent taste. The plant has different vernacular names like patharkuchi in Assamese and Bengali, pashanbheda in Gujrati, pashanbhed in Hindi, kallurvanchi in Malayalam, sirupilai in Tamil, kondapindi in Telegu etc [1].

B. ciliata has many traditional uses. Plant is reported to be used in fever, cough, diarrhea, lungs diseases, asthmatic disorders, vomiting, bruises and boils, digestive disorders, malaria, chronic dysentery, pulmonary disorders, ulcers, dysuria, spleen enlargement, eye diseases, boils, cuts and burn, dissolving kidney stones etc. The plant is also used as tonic and anthelimintic. Local people of Sikkim use this plant as an anti-tussive for cold and cough [2].

B. ciliata contains many bioactive compounds like gallic acid, methyl gallate, quercetin-3-O- $\beta$-Dxylopyranoside, quercetin-3-O- $\alpha$-L-arabinofuranoside, sitoindoside, eryodictiol-7-O- $\beta$-D-glucopyranoside, arbutin, $\quad 6$ '-O-p-hydroxybenzoylarbutin, $\quad \beta$-sitosterol bergenin, 4-O-galloylbergenin, 11-O-galloylbergenin, p-hydroxybenzoic acid, gallicin, (-)-3-0-galloylcatechin, $\beta$-Sitosterol and many others [3].

B. ciliata has several pharmacological activities like, anti-cancer, antipyretic, anti-diabetic, anti-inflammatory, anti-tussive, antibacterial, antiulcer, antioxidant, anti-malarial, anti-antiurolithic, diuretic, hepatoprotective, antiscorbutic etc $[4,5]$.

While screening anti thiamine activity of different plants of Sikkim in our laboratory, we have noted that $B$. ciliata leaves possess in vitro anti thiamine activity. In the present paper we report effect of solvent, temperature, $\mathrm{pH}$ and duration of extraction process on in vitro anti thiamine activity of $B$. ciliate.

\section{MATERIAL AND METHODS \\ Collection of plant material}

Fresh and healthy leaves of $B$. ciliata were collected from the local market of Gangtok, Sikkim \& identified by the taxonomist. Voucher specimen (No. 
Tanaya Ghosh \& Prasanta Kumar Mitra., Saudi J Biomed Res, Jan, 2022; 7(1): 33-36

SM-MB-010/21 -1) was kept in the department of Medical Biotechnology, Sikkim Manipal University for future references.

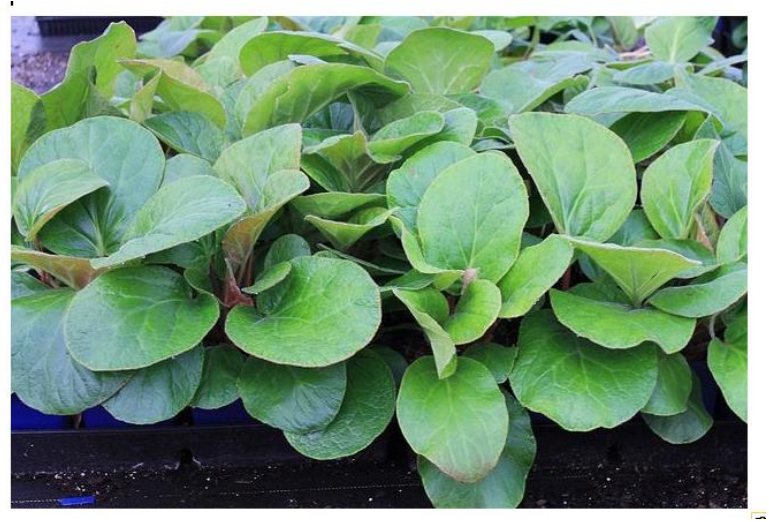

Bergenia ciliate leaves

\section{Preparation of leaves for Anti-thiamine activity}

Leaves of $B$. ciliata were shed dried and powdered. 100 grams of leaf-powder was separately extracted with $500 \mathrm{ml}$ of different solvents (water, ethanol, methanol, chloroform, acetone, petroleum ether) at different temperatures, $\mathrm{pH}$ and duration on a temperature controlled rotary shaker. The extract was filtered and the solvent was evaporated to dryness in vacuo with rotary evaporator at $40-50^{\circ} \mathrm{C}$. A brownish mass was obtained. This mass was stored to test the anti-thiamine activity.

\section{In vitro anti-thiamine activity}

The anti-thiamine activity was determined by estimating the residual thiamine present in a system containing known amount of thiamine hydrochloride and test material collected from $B$. ciliata leaves following the method of Bhattacharya \& Choudhuri [6]. Main steps were: an intimate mixture of thiamine hydrochloride $(100 \mathrm{mg}$ ) and test material collected from B. ciliata leaves after extraction with different solvents (100 mg) was incubated at $30^{\circ} \mathrm{C}$ for 1 hour in $10 \mathrm{ml}$ $\mathrm{M} / 15$ phosphate buffer at $\mathrm{pH}$ 6.5. It was then filtered. 2 $\mathrm{ml}$ of the filtrate was taken and residual thiamine hydrochloride was estimated by thiochrome method described by Harris \& Wang [7]. In short, to $2 \mathrm{ml}$ of the filtrate $0.1 \mathrm{ml}$ of potassium ferricyanide $(2.5 \mathrm{~g} / \mathrm{l})$ and $0.25 \mathrm{ml}$ of sodium hydroxide $(150 \mathrm{~g} / \mathrm{l})$ were added. The solution was mixed thoroughly. $2 \mathrm{ml}$ of iso butanol was then added to it. The solution was shaked for 1 minute. Fluorescence of the supernatant was noted by a fluorimeter at $435 \mathrm{~nm}$ using excitation at $365 \mathrm{~nm}$. Tubes for standard thiamine solution $(400 \mu \mathrm{g} / \mathrm{l})$ and for blank were run simultaneously.

\section{Effect of solvents on extraction process}

Water, ethanol, methanol, chloroform, acetone and petroleum ether were used separately in extraction process.

\section{Effect of time on extraction process}

Extraction processes were done separately for $10,15,20$ and 25 minutes.

\section{Effect of temperature on extraction process}

In separate experiments extraction processes were done at $30,40,50$ and $60^{\circ} \mathrm{C}$ temperature.

\section{Effect of pH on extraction process}

In separate experiments extraction processes were done at $\mathrm{pH}$ 3.0, 5.0, 7.0, 10.0 and 14.0. Acidic and alkaline $\mathrm{pH}$ was maintained by adding $1 \mathrm{~N}$ hydrochloric acid and $1 \mathrm{~N}$ sodium hydroxide respectively.

\section{Reagents}

All reagents required for the experiment were procured from Merck, USA.

\section{RESULTS}

Table 1 shows effect of solvents on extraction process for isolation of anti-thiamine compound from the leaves of B.ciliata. It was found that ethanol extract produced maximum anti-thiamine activity with $65 \%$ inhibition of added thiamine in the in vitro experiment. Anti-thiamine activity in terms of percent inhibition of thiamine for different solvent systems were as follow: water - $30 \%$, ethanol - $65 \%$, methanol - $50 \%$, chloroform $-40 \%$, acetone $-25 \%$, and with petroleum ether $-15 \%$.

Table 1: Effect of solvents on extraction process of the anti-thiamine factor present in B. ciliate leaves

\begin{tabular}{|l|l|l|}
\hline $\begin{array}{l}\text { Solvent } \\
\text { (Extraction for 1 hour) }\end{array}$ & $\begin{array}{l}\text { Amount of mass in mg } \\
\text { (After extraction) }\end{array}$ & $\begin{array}{l}\text { Anti-thiamine activity } \\
\text { (\% inhibition) }\end{array}$ \\
\hline Water & 100 & 30 \\
\hline Ethanol & 100 & 65 \\
\hline Methanol & 100 & 50 \\
\hline Chloroform & 100 & 40 \\
\hline Acetone & 100 & 25 \\
\hline Petroleum ether & 100 & 15 \\
\hline
\end{tabular}

Effect of duration of extraction process for isolation of anti-thiamine compound from $B$. ciliate leaves is shown in Table 2. Time given for extraction in separate experiments was 10 minutes, 15 minutes, 20 minutes and 25 minutes. It appears from the table that anti-thiamine activity in terms of percent inhibition of 
Tanaya Ghosh \& Prasanta Kumar Mitra., Saudi J Biomed Res, Jan, 2022; 7(1): 33-36

exogenous thiamine was maximum $(65 \%)$ for 15 minutes extraction time. For 10 minutes, 20 minutes and 25 minutes of extraction time anti-thiamine activity in terms of percent inhibition of thiamine were determined as $40 \%, 62 \%$ and $61 \%$ respectively.

Table 2: Effect of duration of extraction process (solvent used: ethanol) to test the anti-thiamine factor present in B. ciliate leaves

\begin{tabular}{|l|l|}
\hline Duration (minutes) & Anti-thiamine Activity (\% inhibition) \\
\hline 10 & 40 \\
\hline 15 & 65 \\
\hline 20 & 62 \\
\hline 25 & 61 \\
\hline
\end{tabular}

Table 3 shows the effect of temperature on extraction process for isolation of anti-thiamine compound from the leaves of B. ciliate leaves. Increase in temperature during extraction has elevated the antithiamine activity. When extraction was done at $30^{\circ} \mathrm{C}$ anti-thiamine activity in terms of percent inhibition of added thiamine was $50 \%$ but the same value was $70 \%$ when the extraction temperature was raised to $40^{\circ} \mathrm{C}$. Increase of temperature for extraction above this could not elevate anti-thiamine activity. Results thus showed that the extraction should be done at $40^{\circ} \mathrm{C}$ to get maximum anti-thiamine activity.

Table 3: Effect of temperature on the extraction process (solvent used: ethanol) of anti-thiamine factor present in B. ciliate leaves

\begin{tabular}{|l|l|}
\hline Temperature in ${ }^{\circ} \mathbf{C}$ & Anti-thiamine Activity (\% inhibition) \\
\hline 30 & 50 \\
\hline 40 & 70 \\
\hline 50 & 70 \\
\hline 60 & 71 \\
\hline
\end{tabular}

Effect of $\mathrm{pH}$ on the extraction process for isolation of anti-thiamine compound from the leaves of B. ciliate is shown in Table 4. Different $\mathrm{pH}$ was maintained in separate extraction sets. It was noted that anti- thiamine activity in terms of percent inhibition of exogenous thiamine was maximum $(80 \%)$ at $\mathrm{pH} 3.0$. For $\mathrm{pH} 5.0,7.0,10.0$ and 14.0 of the extraction process, anti-thiamine activity in terms of percent inhibition of thiamine was much less.

Table 4: Effect of pH on the extraction process (solvent used: ethanol) of anti-thiamine factor present in $B$. ciliate leaves

\begin{tabular}{|l|l|}
\hline pH & Anti-thiamine activity (\% inhibition) \\
\hline 3 & 80 \\
\hline 5 & 78 \\
\hline 7 & 67 \\
\hline 10 & 50 \\
\hline 14 & 29 \\
\hline
\end{tabular}

Results were mean of five sets of experiment.

\section{DISCUSSION}

Extraction process is a part of the work of isolation of bio-active compounds from plant materials. Extracts with different solvents generally show different composition of bio-active molecules [8]. Therefore, a suitable extracting solvent is needed to be selected for extraction of the active compound with maximum activity [9]. In the present experiment use of different extracting solvents (distilled water, chloroform, ethanol, methanol, acetone and petroleum ether) has led to the selection of ethanol to get maximum anti thiamine activity of $B$. ciliate leaves. This was followed by methanol and chloroform respectively Other solvents used in extraction process like water, acetone and petroleum ether showed little anti-thiamine activity.

Extraction time is very important to extract active compounds in maximum amount [10]. In this experiment we have noted that extracts with ethanol for 15 minutes gave maximum in vitro anti thiamine activity of $B$. ciliate leaves.

Extraction temperature is another important factor influencing the recovery of the bioactive compound from the sources [9]. In this experiment we have seen that extract of $B$. ciliate leave at $40^{\circ} \mathrm{C}$ had maximum in vitro anti thiamine activity.

Extraction $\mathrm{pH}$ is also important to obtain more amount of bioactive compound from the source as most of the compounds are present in complex form with many other biomolecules [11]. In the present experiment it was noted that extract of of $B$. ciliate leaves at $\mathrm{pH} 3$ had maximum in vitro anti thiamine activity.

Many plants have shown in vitro anti thiamine activity. Few are, blue berries, Coffea arabica Linnaeus, Brassica juncea (Linnaeus) Czernajew, Bombax ceiba, Ageratum conyzoides Linn. etc [6, 12, 13]. Linnaeus etc. Present study confirmed in vitro antithiamine activity of the leaves of $B$. ciliate. 
Tanaya Ghosh \& Prasanta Kumar Mitra., Saudi J Biomed Res, Jan, 2022; 7(1): 33-36

It is known that biological activity of medicinal plants depends on season [13-15]. We are now working on seasonal variation on in vitro antithiamine activity of the leaves of $B$. ciliate.

\section{CONCLUSION}

B. ciliate leaves have many medicinal properties. People therefore take this leaves to get rid of different ailments. They should be aware of the presence of anti-thiamine compound in $B$. ciliate leaves. Further research is needed to ascertain the amount of anti-thiamine compound in $B$. ciliate leaves.

Conflict of interest: The authors declare that they have no conflict of interest.

\section{REFERENCES}

1. Khan, M. Y., \& Kumar, V. (2016). Phytopharmacological and chemical profile of Bergenia ciliata. Int J Phytopharm, 6(5), 90-98.

2. Singh, L., Kumar, A., \& Paul, A. (2018). Bergenia ciliata: The medicinal herb of cold desert. International Journal of Chemical Studies, 6(3), 3609-3613.

3. Fujii, M., Miyaichi, Y., \& Tomimori, T. (1996). Studies on Nepalese Crude Drugs. XXII: On the Phenolic Constituents of the Rhizome of Bergenia ciliata (HAW.) STERNB. Natural Medicines, 50(6), 404-407.

4. Sinha, S., Murugesan, T., Maiti, K., Gayen, J. R., Pal, B., Pal, M., \& Saha, B. P. (2001). Antibacterial activity of Bergenia ciliata rhizome, Fitoterapia, 72(5), 550-552.

5. Bashir, S., Gilani, A. H. (2009). Antiurolithic effect of Bergenia ligulata rhizome: an explanation of the underlying mechanisms. Journal of Ethnopharmacology, 122(1), 106-16.

6. Bhattacharya, J., \& Chaudhury, D. K. (1974). Antithiamine factor present in Brassica juncea.Biochem Biophys. Acta, 343, 211-220.
7. Harris, L. J., \& Wang, Y. L. (1941). A new method for estimation of residual thiamine. Biochem J, 35, 1050-1058.

8. Zarnowski, R., \& Suzuki, Y. (2004). Expedient soxlet extraction of resorcinolic lipids from wheat grains. Journal of Food composition and Analysis, 17, 649-664.

9. Wang, L., \& Weller, C. L. (2006). Recent advances in extraction of nutraceuticals from plants, Trends Food Science and Technology, 17, 300-312.

10. Cannell, R. J. P. (1998). Natural Products Isolation. Human Press Inc, New Jersey., Pp. $165-$ 208.

11. Sasidharan, S., Chen, Y., Saravanan, D., Sundram, K. M., \& Latha, L. Y. (2011). Extraction, isolation and characterization of bioactive compounds from plants' extracts. African journal of traditional, complementary and alternative medicines, 8(1), 110.

12. Sarkar, L., \& Chaudhury, D. K. (1976). Studies on anti thiamine factor present in Bombex melaberries. Int J Vit Nutr Res, 46, 417-425.

13. Guria, M., Mitra, P., Ghosh, T., Salhan, R., Takhelmayum, A. S., Chakrabarti, A., \& Mitra, P. K. (2015). In vitro anti thiamine effect of Ageratum conyzoides L. leaves: Effect of season. International Journal of Advanced Pharmaceutics, 5, 24-27.

14. Mitra, P., Ghosh, T., \& Mitra, P. K. (2016). Seasonal variation in hepatoprotective activity of Cassia alata Linn. leaves on antitubercular drugs induced hepatotoxicity in rats. Pharmacy Practice \& Drug Research, 6(1), 40-44.

15. Prasenjit, M., Tanaya, G., \& Kumar, M. P. (2016). Seasonal variation in anti-ulcerogenic activity of Ageratum conyzoides L. leaves. International Journal of Biopharmaceutics, 7, 63-68. 